\title{
Analysis of the Characteristics of Low-Carbon Independent Innovation
}

\author{
Tingfa Zhang ${ }^{1, ~ a ~ * ~}$ \\ ${ }^{1}$ Research Department, Qilu Normal University, China \\ a ztfsdu2011@163.com \\ *The Corresponding author
}

\begin{abstract}
Keywords: Low-carbon; Independent innovation; Low-carbon economy; Characteristics
\end{abstract}
\begin{abstract}
Low-carbon independent innovation has not only the same place with independent innovation in the general field, but also has many unique features. On the basis of comprehensive review and combing of relevant theoretical literature and preliminary research results, it is necessary to comprehensively analyze the independent innovation of low-carbon field to design and select the scientific application model. Based on their own national conditions to carry out low-carbon independent innovation, to build China's low-carbon independent innovation model has become China's development of low-carbon economy inevitable choice. This paper makes a comprehensive and in-depth analysis of the characteristics of low-carbon independent innovation from the aspects of general characteristics, complexity characteristics and income risk characteristics.
\end{abstract}

\section{Introduction}

Low-carbon economy is to respond to the challenges of global climate change, to alleviate the economic and social development of resources and environment constraints, to achieve sustainable development of human economic and social development of a new economic model. The development of low-carbon economy needs to accelerate the transformation and upgrading of industrial structure, increase the proportion of renewable energy energy consumption, reduce the intensity of traditional industries carbon emissions, innovation is the fundamental way to achieve these development goals and path. To achieve the transformation of economic development model, to promote rapid and in-depth development of low-carbon economy, must be based on independent innovation.

As a developing country, China's economic development in the face of the situation is quite grim. Not only with the rest of the world is facing the climate and other ecological issues in common, but also has the characteristics of China's energy problems. This is reflected in the one hand, high pollution, high emissions makes our ecological environment has been seriously damaged; the other hand, high energy consumption to our energy crisis, economic efficiency is challenged. Therefore, this is more reflects the energy-saving emission reduction and low-carbon development of the importance of China's economic development, low-carbon economy is an inevitable choice for the development of our country. China 's Energy Structure in 2012 is shown in figure 1.

\section{General Characteristics of Low-Carbon Independent Innovation}

Relative to other business behavior, independent innovation has a number of distinctive features, such as high returns and high risk. Low-carbon independent innovation is independent innovation in the field of low-carbon specific, in addition to the characteristics of the general independent innovation, but also has a unique feature of low-carbon areas. This section analyzes the general characteristics of low-carbon independent innovation from three perspectives: high input and low output, high technology and low efficiency, high barrier and low emission. 


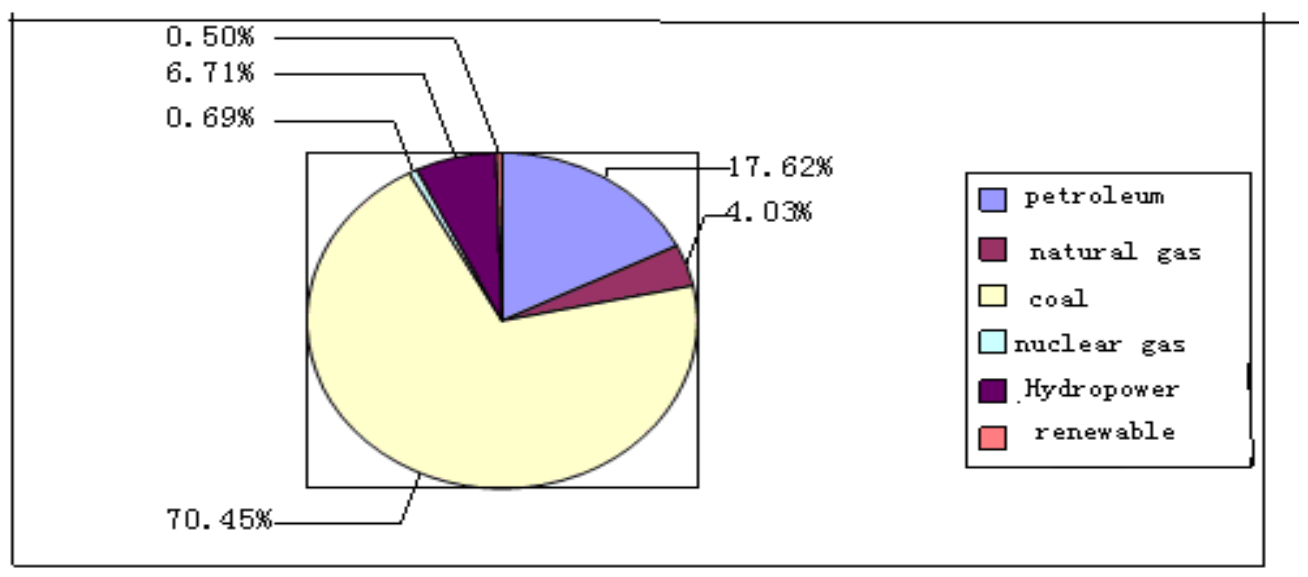

Figure 1. Finite China 's Energy Structure in 2012

Low-carbon Independent Innovation of High Input and Low Emissions. From the low-carbon independent innovation technology leadership, low-carbon independent innovation due to low-carbon technology has a considerable degree of originality, which requires innovative entities to invest more money, time and talent to explore the study of this new field. From the low-carbon independent innovation process point of view, low-carbon independent innovation by the market recognition and reception requires a more long process. In this process, the innovation of the main need to invest resources for market cultivation and development, which determines the low-carbon independent innovation than other areas of innovation activities need more resources. Control of fossil energy consumption, slowing greenhouse gas emissions on the climate and environmental damage is one of the important goals of low-carbon economic development, therefore, low-carbon independent innovation also showed low emission characteristics. Low-carbon technology innovation is the core content of low-carbon independent innovation, low-carbon technology, including clean energy technology, energy-saving technologies and carbon emissions recycling technology. Low-carbon technology, the three main directions are to reduce carbon emissions as the main target orientation, low-carbon independent innovation and thus the performance of low emission characteristics.

\section{High-tech and Low Efficiency Characteristics of Low-Carbon independent Innovation}

Low-carbon independent innovation in the core of low-carbon technology innovation, including clean energy technologies, energy-saving technologies and carbon emissions recycling technology. Foreign scholars generally believe that to clean renewable energy technology as the main low-carbon technology innovation is a breakthrough innovation, and high-tech characteristics of breakthrough innovation is one of the important features.

Low-tech technological innovation has two aspects of high-tech features. First of all, the development of new energy technologies related to the stability of human society for sustainable development, the development process of human society will have a huge impact. For a long time, the development and progress of human society is based on the large-scale exploitation and utilization of fossil fuels based mainly on coal and oil. Fossil energy is non-renewable energy, with the gradual increase in the amount of fossil energy as soon as possible to meet the sustainable development of human society, the demand for energy.

Table 1 Dependence on Foreign Oil in 2011

\begin{tabular}{|l|l|l|}
\hline $\begin{array}{l}\text { Global daily oil } \\
\text { consumption }\end{array}$ & $\begin{array}{l}\text { China 's total oil } \\
\text { consumption }\end{array}$ & Dependence on Foreign Oil \\
\hline 8800 Million barrels & 4.9 Billion tons & $54.8 \%$ \\
\hline
\end{tabular}


Secondly, low-carbon technology has a broad market prospects, can bring huge economic benefits for innovation, as IT technology innovation for IBM, Apple, Microsoft and other innovative entities brought the same benefits. With the reduction of fossil energy reserves, fossil energy use costs increased rapidly, and human energy demand is a rigid demand, two factors together determine the new energy market prospects.

As China's low-carbon areas of innovative talent and equipment is scarce, the innovation of the main creative resources and equipment resources are very limited. However, under the traditional innovation mode, the innovative talents among the innovative subjects can not realize the mutual exchange and inspiration, and the equipment is difficult to realize the cross utilization. The efficiency of the talents and the efficiency of the equipment are relatively low.

\section{High Barrier and Low Output Characteristics of Low-Carbon Independent Innovation}

The vigorous development of low-carbon economy for our country to achieve economic "corner overtaking", occupy the high-end chain of new industry chain provides a good opportunity. Developed countries represented by the United States for the political, economic and other considerations, long-term implementation of China's strict high-tech blockade. In order to maintain its own dominance over the world economy and contain the rapid rise of our country in the era of low-carbon economy, the United States and other developed countries are bound to adopt a more stringent low-carbon technology blockade to prevent our country from developing rapidly in the low-carbon field. China's low-carbon independent innovation is facing severe technical blockade, showing the characteristics of high barriers.

On the other hand, China's low-carbon independent innovation is also characterized by high barriers in developed countries on China's low-carbon products trade barriers. May 2012 the United States announced that China's solar photovoltaic products levy $31.14 \%-249.96 \%$ of the high anti-dumping duties, following the United States, the EU countries have also announced the Chinese solar photovoltaic products imposed high anti-dumping duties. The ban on low-carbon technology exports and the protection of low-carbon products to take trade protectionism in these two aspects of China's low-carbon independent innovation to carry out great difficulties, but also to the main innovation brought huge economic losses. China's low-carbon independent innovation shows the characteristics of high barriers.

The lower innovation output is one of the independent innovation characteristics under the traditional innovation mode, which is verified by the technical success rate or the commercial success rate as the measure of the innovation output. Many domestic research methods based on different angles using a variety of research methods on China's independent innovation output characteristics of the study, the results generally show that China's innovation and output level is relatively low.

\section{Characteristics of Risk Income of Low-carbon Independent Innovation}

Independent innovation is a high-risk and high-yield coexistence of economic activities. Independent innovation in low-carbon areas reflects the high risk and high-yield characteristics of independent innovation in the traditional field, and also has many unique characteristics such as earnings uncertainty, income spillovers, higher risk and diversification of income.

Uncertainty of Income of Low-carbon Independent Innovation. . In the upcoming low-carbon economic development wave to maximize the economic interests of enterprises and other market-oriented to carry out low-carbon independent innovation source. In the open innovation mode, innovation revenue can be achieved through various channels inside and outside the enterprise, such as the production and sales of low-carbon products, the transfer of low-carbon innovation and so on. However, the low-carbon independent innovation of high input costs and rapid changes in the market situation and other multiple subjective and objective factors determine the low-carbon independent innovation income is facing great uncertainty. 
The development of low-carbon industry and the upgrading of low-carbon industries of traditional industries are the main contents of low-carbon economic development. Technological innovation is the means and way to achieve this goal. However, low-carbon technological innovation is facing great uncertainty. Innovation of the main input resources for low-carbon technology innovation is facing innovative technological achievements do not meet the risk of economic development trends, which led to the uncertainty of income. The Political Causes of Uncertainty of Low - carbon Independent Innovation. Market failure occurs, the rational choice of the main body may lead to the overall irrationality, in this case the government as indispensable.

\section{Profit Spillover Characteristics of Low-carbon Independent Innovation}

Compared with the traditional areas of independent innovation, low-carbon independent innovation spillover effect is stronger, the impact of the main scope of a wider range. Low-carbon independent innovation and the use of results will directly reduce carbon emissions, carbon emissions brought about by the improvement of the environment will produce a wider range of spillover effects.

Firstly, low-carbon independent innovation technology spill. There are two kinds of technologies in the market main body: (1) to form a new technology through the low-carbon independent innovation activities in the market main body; (2) the market main body obtains the technological innovation from other external entities New technology, which is the above technology spill.

Secondly, low-carbon independent innovation market spill. Innovation in the completion of low-carbon independent innovation and technology research and development and production of new products, its investment in resource development and cultivation of the market space by competitors free of charge phenomenon.

Finally, low-carbon independent innovation of the environment overflow. Low-carbon innovation of the main creative activities brought about by the environmental benefits of the external subject free of charge to share the phenomenon.

\section{Low-carbon Independent Innovation Income Diversification}

with the traditional areas of independent innovation, the successful development of low-carbon independent innovation and the use of results will bring great economic benefits to the main innovation, but at the same time more for the innovation of the main reputation income. With the increase of the radius of human economic activities, reputation resources has gradually become one of the most important resources of market players. Good reputation is helpful to enhance the competitiveness of market players and ultimately bring more economic benefits to return.

\section{High Risk of Low-carbon Independent Innovation}

Independent innovation is a very complex process that consists of multiple links, and there are many uncertainties in the process that determine that independent innovation is a high-risk business activity.

First of all, low-carbon independent innovation facing the macro environment is more complex and changeable, technical uncertainty and product market uncertainty is also higher. Secondly, low-carbon independent innovation in the face of political situation, laws and regulations and economic policy changes and other macroeconomic risks at the same time, but also by the international climate political negotiations progress.

\section{The Dual Objective Characteristics of Low Carbon Independent Innovation}

Low-carbon economy is the human in order to maintain their own living standards continue to improve on the basis of human society and the natural environment to achieve the harmonious development of the new economic development model, with ecological and economic benefits of the dual objectives. 


\section{Eco-efficiency goals for Low-carbon Independent Innovation---Low Emission}

Independent innovation is a very complex process that consists of multiple links, and there are many uncertainties in the process that determine that independent innovation is a high-risk business activity.

\section{High Risk of Low-carbon Independent Innovation}

Industrial innovation, policy and legal mechanism and the market mechanism is a low-carbon economy troika. Under the basic system of market economy, effectively promote the development of low-carbon economy, the need to play the role of market mechanisms, follow the basic laws of the market. The main body of economic activity is "limited rational person", which in the realization of their own interests to maximize the goal under the guidance of economic activities. In the United States, Germany, Japan and other developed countries, its technology research and development spending $70 \%$ of the enterprises to complete. At present, China's technology research and development funds are also mainly funded by the enterprise to complete. National research and development personnel are also engaged in research work in the enterprise. In view of the special status of enterprises in economic development, to achieve rapid development of low-carbon economy requires enterprises to play its special role.

\section{References}

[1] K Parikh. Sustainable development and low carbon growth strategy for India, J. Energy, Vol.40 (1994) No.1, 31-38.

[2] Furman, J.L., Porter, M.E., Stern, S. The determinants of national innovative capacity, J. Research Policy, 2002,31(6):899--933. Vol.31 (2002) No.6, 899-933.

[3] UK Rout. Prospects of India's energy and emissions for a long time frame, J. Energy Policy, 2011,39(9):5647-5663 Vol.39 (2011) No.9, 5647-5663.

[4] P Balachandra, D Rabindranath, NH Rabindranath. Energy efficiency in India: Assessing the policy regimes and their impacts[J]. Energy Policy, 2010, 38(11):6248-6438.

[5] Hu, X., Murgovski, N., Johannesson, L., Egardt, B. Energy efficiency analysis of a series plug-in hybrid electric bus with different energy management strate gies and battery sizes,J. Energy, Vol.111 (2013) No.11, 1001-1009.

[6] Ding, Y., Yang, H. Promoting energy-saving and environmentally friendly generation Energy Policy, Vol.57 (2013) No.6, 109-118.

[7] Gao, C., Li, Y., Evolution of China's power dispatch principle and the newenergy saving power dispatch policy, J. Energy Policy, Vol.38 (2010) No.11, 17346-7357.

[8] Ji, S., Cherry, C.R.,J., Bechle, M., Wu, Y., Marshall, J.D. Electric vehicles in China:emissions and health impacts, J. Environ. Sci. Technol, 2012, 46 (4), 2018-2024.

[9] Stern N. The Economics of Climate Change[M]. London: Cambridge University Press, 2006.

[10] IPCC. Climate Change 2007: migitation. Contribution of Working Group III. To the Fourth Assessment Report of the Intergovernmental Panel on Climate Change[R]. London: Cambridge University Press.,2007. 